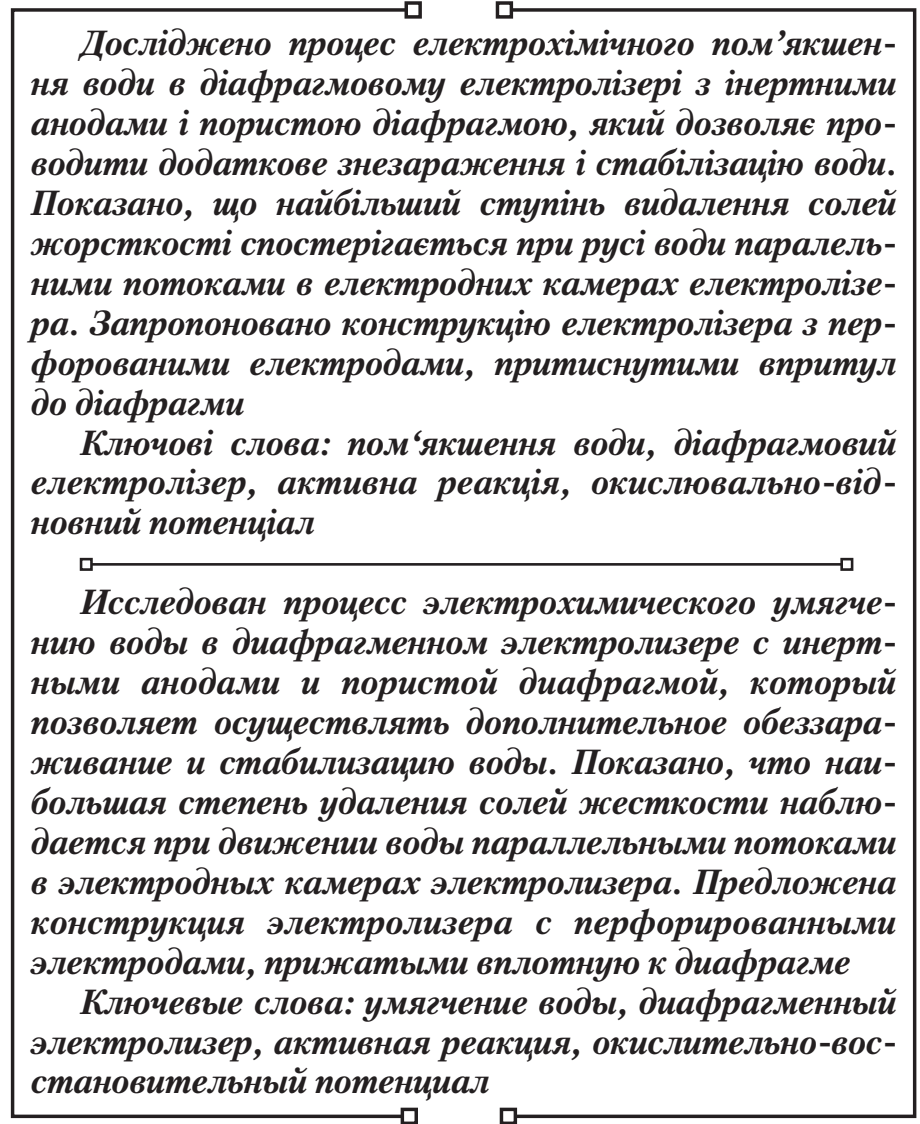

UDC 628.337

DOI: $10.15587 / 1729-4061.2017 .96120$

\title{
ELECTROCHEMICAL WATER SOFTENING IN A DIAPHRAGM ELECTROLYZER
}

\author{
V. Fylypchuk \\ Doctor of Technical Sciences, Professor \\ Department of labour protection and life safety* \\ E-mail: elfi@infokom.rv.ua \\ L. F y l y p c h u k \\ $\mathrm{PhD}$, Associate Professor \\ Department of automation, electrical and \\ computer-integrated technologies* \\ E-mail: leonmail@ukr.net \\ *National University of \\ Water and Environmental Engineering \\ Soborna str., 11, Rivne, Ukraine, 33028
}

\section{Introduction}

Water hardness negatively affects the majority of production processes where water is used with a high content of calcium and magnesium ions. Surface incrustation with hardness salts can worsen quality of products and wreck process equipment. Water softening is widely used in the processes of water treatment for heat power plants, radio engineering industry, galvanic production, drinking water supply. Requirements to the content of hardness salts in softened water vary widely in industry. Also, the content of hardness salts in potable water is limited since excess calcium and magnesium can adversely affect functioning of human organs [1].

The reagent and ion-exchange water softening methods are most commonly used [2]. In recent decades, reverse osmosis and nanofiltration have been used [3, 4]. With the reagent method, alkali, sodium carbonate, calcium hydroxide and other chemicals are dosed into water. As a result, calcium ions bind to insoluble compounds which then form a precipitate.

However, water in this case is inevitably contaminated with sodium ions and foreign anions, which can adversely affect quality of the softened water. Treated water requires stabilization by acidification to prevent undesirable residual precipitation of calcium salts in pipelines and equipment. Also, disinfection is necessary with the help of special reagents which further increase mineralization of purified water. For example, the "secondary pollution" of softened water associated with the use of chemical reagents is characterized by the ratio of the weight of the reagent remaining in water to the total weight of the reactant introduced equal to $0.95-0.98$ for water stabilization, $0.5-0,7$ for alkalization and 1,0 for disinfection.
Deeper softening is ensured by the ion-exchange method which is often used in industrial water treatment. However, ion-exchange softening requires a significant amount of chemical reagents for regeneration of ion-exchange resins which is 2.5 to 3 times higher than the amount of ions being removed. Regeneration solutions are discharged into water reservoirs thereby increasing their mineral composition, which negatively affects the environment. To improve efficiency of the ion-exchange process, combinations of different methods are used [5].

Application of reverse osmosis to remove hardness salts is only possible in the process of general desalination of water, which is not always beneficial from the economic and technological points of view. In this case, salt concentrates are formed which must be sent for disposal or recycling. In addition, it is necessary to periodically regenerate reverse osmosis membranes with special chemical solutions that require separate deep and complex purification.

Thus, development of new water softening technologies is associated with the use of reagentless methods based on a complete or partial exclusion of chemical reagents from the process of hardness salt removal. From this point of view, application of electrochemical methods for removing hardness salts from water is promising. These methods are based on water softening under the influence of electric current due to the electrochemical processes taking place at the electrode-electrolyte boundary [6].

The use of electrochemical methods makes it possible to completely abandon the use of chemical reagents, avoid secondary contamination of softened water with chemicals and prevent discharge of waste and regenerative solutions into water reservoirs. As a result, the softening process is greatly simplified, equipment operation safety increases and chemical pollution of the aquatic environment is prevented. 


\section{Literature review and problem statement}

It is known that the processes and equipment for electrochemical treatment of natural and wastewater are characterized by compactness of instrumentation, simplicity of maintenance and they allow refusal from reagent handling. Adjustment of parameters of their operation is reduced basically just to a change in the electrolysis current or voltage values. Exclusion of chemical reagents from the cycle of water treatment prevents growth of salt content and complication of the ion-molecular composition of purified water. This expands the possibility of using softened water in circulating and closed water consuming systems of industrial enterprises.

The possibility of electrochemical removal of hardness salts has long been recognized but the industrial use of this method is rather limited because of technological and technical complexities. Existing electrochemical softening methods provide for water electrolysis either with no separation of the electrode reaction products (in a diaphragmless electrolyzer) or with their separation (in a diaphragm electrolyzer).

Treatment of water in a diaphragmless electrolyzer with insoluble (inert) electrodes requires low current densities and a considerable process time. In this case, hardness salts precipitate mainly due to chemical and thermal processes directly on the cathodes in a form of a dense precipitate of poorly soluble calcium and magnesium salts [7]. Such incrustation of cathodes results in a gradual decrease in current, increase in electrolysis voltage and higher costs of electricity per unit of the removed hardness salts. Additionally, complexity of operation of electrolyzers includes necessity of labor-intensive operations of electrode surface cleaning from the precipitated hardness salts. As a consequence, the current efficiency of the hardness salt precipitation process is low and energy-costly.

To reduce cathode incrustation, combined treatment of water in electrolyzers with soluble and insoluble anodes is recommended which facilitates electrode purification from the hardness salts [8]. A separate use of soluble metal anodes in an electrolyzer is recommended for electrocoagulation of hardness salts [9]. During electrolysis, soluble anodes are ionized and metal ions pass into water. As a result, the anodes dissolve and they have to be regularly renewed which is non-value-added. Water softening in diaphragm electrolyzers is more efficient $[10,11]$. Intensification of the process of hardness salt precipitation is achieved by separating the alkaline catholyte from the acid anolyte with a diaphragm. The main process consists in electrochemical alkalinization of water in the electrolyzer cathode chamber in which chemical precipitation of calcium and magnesium salts in the volume of catholyte occurs due to the increase in $\mathrm{pH}$. However, the process of electrochemical variation of $\mathrm{pH}$ in the electrode chambers and the mechanism of precipitation of calcium and magnesium ions in the catholyte and anolyte were not studied in detail. The accompanying shift of the Eh value causing a change in the oxidation-reduction properties of catholyte and anolyte in the softening process and affecting the properties of the treated water was insufficiently studied.

Ion-exchange membranes have become widespread as diaphragms in diaphragm electrolyzers [12-14]. The use of ion-exchange membranes complicates design and operation of electrolyzers. An irreversible poisoning of membranes with water impurities and a decrease in their ion-exchange properties take place. Also, suspended hardness salts precip- itate on the membrane surfaces. As a result, gradual decrease in efficiency of membrane functioning and the degree of hardness salt removal is observed.

The use of inactive porous diaphragms and joint application of cathodic and anodic processes for water treatment makes it possible to simplify the softening process [6]. In known electrolyzers, anodes and cathodes separated by a porous diaphragm are located at a considerable distance from each other. This requires a high voltage of electrolysis and increased energy consumption for water softening.

Separate water feed to the electrode chambers and separate extraction of catholyte and anolyte are used in presentday flow diaphragm electrolysers $[15,16]$. This technology allows obtaining of a high degree of softening of catholyte. At the same time, acid anolyte is unproductively discharged from the anode chamber, which raises energy consumption in water softening. To improve efficiency of the process, use of ion-exchange materials as the diaphragm and a constant recirculation of anolyte through the anode chamber are recommended [17]. However, anolyte should be discarded or sent for cleaning after several cycles of water treatment.

After removal of poorly soluble hardness salts, the catholyte has an alkaline reaction, which necessitates its stabilization and subsequent disinfection of the softened water.

In this connection, it is necessary to further study the electrochemical process of water softening under various regimes of water flow in the electrode chambers of the flow diaphragm electrolyzer in order to improve removal of hardness salts without additional disposal of the spent solutions.

\section{Objective and tasks of the study}

Objective of this work consisted in the study of the water softening process when the products of electrode reactions are separated in a diaphragm electrolyzer using insoluble anodes and an inactive diaphragm made of a porous material.

To achieve this objective, the following tasks were accomplished:

- study of the change in the value of the active reaction $(\mathrm{pH})$ and redox potential $(\mathrm{Eh})$ in the electrode chambers of the electrolyzer and estimation of the effect of these processes on softening, stabilization and disinfection of purified water;

- study of the process of water softening at various schemes of water movement in the electrode cameras of the electrolyzer using water filtration through a porous diaphragm. Efficiency study of operation of the diaphragm electrolyzers with perforated electrodes pressed against the diaphragm from both its sides.

\section{Materials and methods of electrochemical water softening}

The investigations were carried out with a pilot diaphragm electrolyzer having dimensions of $1 \mathrm{~m}$ in width by $0.8 \mathrm{~m}$ in height. Stainless steel was used for the cathode, titanium for the anode and porous Chlorine cloth for the inactive diaphragm. The electrode assembly included cathode and anode with perforated $20 \mathrm{~mm}$ diameter holes pressed to the diaphragm from its both sides. The inside surfaces of the electrodes facing the diaphragm were insulated with a special coating. This design of the electrode system made it possible to minimize the distance between the electrodes and significantly reduce the electrolysis voltage. The elec- 
trode assembly was installed in the electrolyzer body in such a way that harmful water flow between the cathode and anode chambers through the joints between the electrode and the housing walls was prevented. The installation capacity was $0.1-0.3 \mathrm{~m}^{3} / \mathrm{h}$.

A regulated electric current rectifier was used for power supply of the cell. The electrodes were connected to the rectifier by a monopolar circuit. Current density at the electrodes was $25-30 \mathrm{~A} / \mathrm{m}^{2}$, electrolysis voltage was $8-12 \mathrm{~V}$.

For this study, natural water was used from a subterranean source (well) with a total hardness of $4.2-11.4 \mathrm{mmole} / \mathrm{dm}^{3}$ and a total mineralization of up to $500 \mathrm{mg} / \mathrm{dm}^{3}$. When studying the effect of $\mathrm{pH}$ change on water mineralization, $\mathrm{Na}_{2} \mathrm{SO}_{4}$ salt was added to it. To study the change in Eh, aqueous solutions of $\mathrm{NaCl}$ and $\mathrm{Na}_{2} \mathrm{SO}_{4}$ of various concentrations were used.

The softening process was studied in static and flow conditions. In static conditions, water was fed to the electrolyzer and the catholyte and anolyte were uniformly drained at regular intervals from the lower body part thru special fittings after electrochemical treatment. In flow conditions, the source water was fed to the lower part of the electrode chambers, and the treated water was removed from the upper part by means of trays installed at the side opposite to the water supply points. Regulation of the ratio of water flows thru the electrode chambers was made by adjusting the height of the corresponding trays for removal of catholyte and anolyte. Measurement of catholyte and anolyte flows was made by a volumetric method.

The influence of various patterns of water flow in the electrolyzer was studied for sequential and parallel water flows in the electrode chambers (Fig. 1). During the sequential movement, water was fed to the cathode (or anode) chamber, then the whole flow passed through the porous diaphragm to the anode (or cathode) chamber, from where the treated water was removed and filtered. In the parallel flow, water was fed to the cathode (or anode) chamber and then a part of it was filtered through a porous diaphragm into the anode (or cathode) chamber. The treated water was removed from the cathode and anode chambers in two streams. The catholyte stream was purified in a filter and then mixed with the anolyte stream.

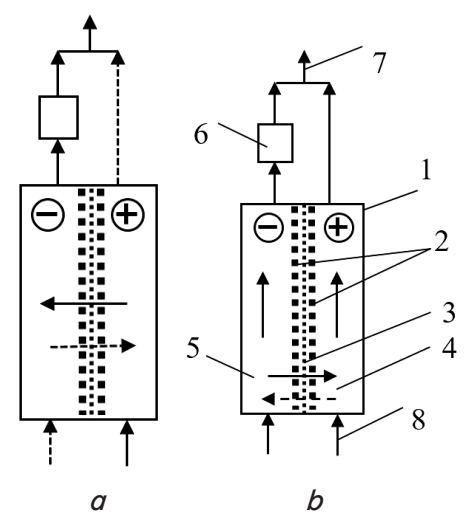

Fig. 1. Plan view schemes of water treatment in a flow diaphragm electrolyzer: $a-$ for a sequential water flow; $b$ - for a parallel water flow; 1 - diaphragm electrolyzer, 2 - electrodes, 3 - porous diaphragm, 4 - anode chamber, 5 - cathode chamber, 6 - filter, 7 - water inlet, 8 - water outlet

To measure pH and Eh, ProMinent ionometer (Germany) was used. The concentrations of hardness ions and other water indices were made using standard methods in a certified hydrochemical laboratory after filtering the water treated in the electrolyzer through a 'white-tape' paper filter.

To estimate energy consumptions for water treatment, the calculated index of the specific quantity of electricity per unit volume of treated water was used (current consumption, D)

$$
\mathrm{D}=\frac{\mathrm{IT}}{\mathrm{W}}=\frac{\mathrm{I}}{\mathrm{Q}}, \mathrm{C} / \mathrm{l},
$$

where I is current value, $\mathrm{A}$; $\mathrm{t}$ is water treatment time, sec; $\mathrm{W}$ is volume of the treated water, 1 ; $\mathrm{Q}$ is water flow, $\mathrm{l} / \mathrm{sec}$.

Specific energy consumptions (E) were determined by the formula:

$$
\mathrm{E}=\frac{\mathrm{DU}}{3600}, \mathrm{~kW}-\mathrm{hr} / \mathrm{m}^{3},
$$

where $\mathrm{U}$ is the electrolysis voltage, $\mathrm{V}$.

\section{The results obtained in the studies of electrochemical water softening}

\section{1. Change in $\mathrm{pH}$ and Eh during water softening in} the diaphragm electrolyzer

During water electrolysis in the diaphragm electrolyzer, catholyte was alkalinized thru reduction of water molecules on the cathode with formation of hydroxyl ions and evolution of hydrogen gas

$$
2 \mathrm{H}_{2} \mathrm{O}+2 \mathrm{e} \rightarrow 2 \mathrm{OH}^{-}+\mathrm{H}_{2} \text {. }
$$

On the insoluble anode, water molecules were oxidized with the release of gaseous oxygen and formation of hydrogen ions, which leads to anolyte acidation

$$
2 \mathrm{H}_{2} \mathrm{O}-4 \mathrm{e} \rightarrow 4 \mathrm{H}^{+}+\mathrm{O}_{2} \text {. }
$$

As a result of electrolysis, catholyte $\mathrm{pH}$ increased to 10.8-11.2, the anolyte $\mathrm{pH}$ dropped to $3.0-3.2$ (Fig. 2). A characteristic change in $\mathrm{pH}$ from $5.7-5.9$ to $3.2-3.4$ was observed in the curve of anolyte $\mathrm{pH}$ change. This was because of transition of carbonate ions $\mathrm{CO}_{3}^{2-}$ to carbon dioxide $\mathrm{CO}_{2}$ due to a change in the carbon dioxide equilibrium with acidation of water. The increase in salt content in natural water due to $\mathrm{Na}_{2} \mathrm{SO}_{4}$ salt intensified the process of changing $\mathrm{pH}$ of both catholyte and anolyte.

Growth of water mineralization increased concentration of the formed alkali in the cathode chamber and acid in the anode chamber and, accordingly, the amount of precipitated hardness salts (Fig. 3). In this case, accumulation of alkali and acid occured in an equivalent amount, provided that only electrode processes of oxygen and hydrogen release took place on the electrodes.

The limiting amount of alkali (acid) that accumulates in the cathode (anodic) chamber of the diaphragm electrolyzer depending on mineralization of the aqueous phase $\left(\mathrm{S}_{\mathrm{M}}, \mathrm{mg} / \mathrm{l}\right)$ can be determined by the formula:

$$
\nabla \mathrm{C}_{\mathrm{al}(\text { as })}=(0.011-0.013) \mathrm{S}_{\mathrm{M}}, \mathrm{mg} \text {-equiv } / \mathrm{dm}^{3} .
$$




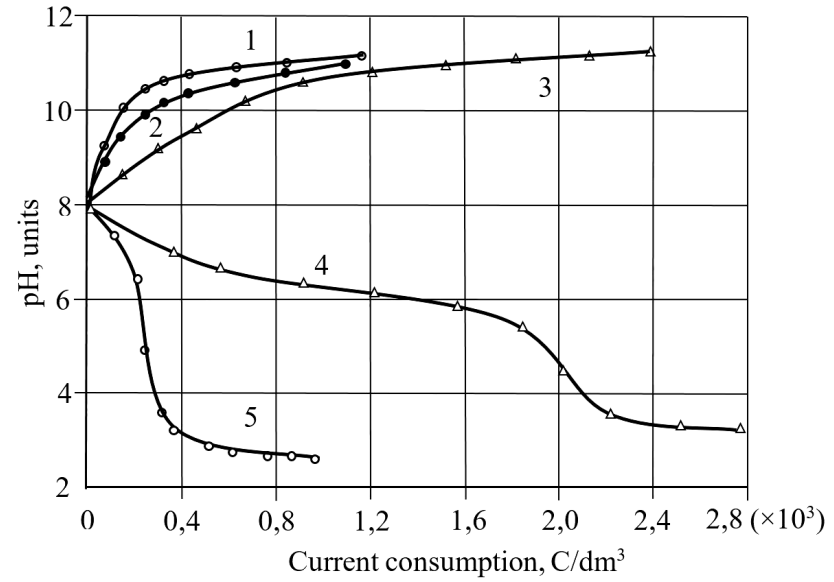

Fig. 2. Dependence of $\mathrm{pH}$ of catholite (1-3) an anolite $(4,5)$ on current consumption in treatment of natural water in a static diaphragm electrolyzer:

1, 5 - water with $0.01 \mathrm{M}$ solution of $\mathrm{Na}_{2} \mathrm{SO}_{4}$ and carbonate hardness of $2.4 \mathrm{mmole} / \mathrm{dm}^{3} ; 2$ - water with carbonate hardness of $2.4 \mathrm{mmole} / \mathrm{dm}^{3} ; 3,4$ - water with carbonate hardness of $4.6 \mathrm{mmole} / \mathrm{dm}^{3}$

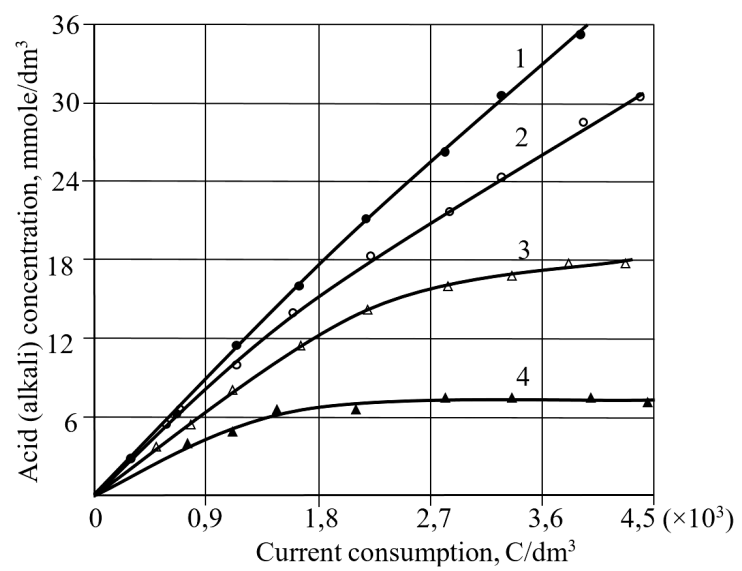

Fig. 3. Dependence of acid (alkali) accumulation on current consumption in a static diaphragm electrolyzer when treating an aqueous solution with an initial $\mathrm{pH}=7.0$ and concentration of indifferent electrolyte $\mathrm{Na}_{2} \mathrm{SO}_{4}: 1-5,000 ; 2-7,000$,

$$
3-2,000 ; 4-500 \mathrm{mg} / \mathrm{I}
$$

Due to the increase in water $\mathrm{pH}$ in the cathode chamber, carbon dioxide equilibrium shifts toward formation of carbonate ions with formation of hardly soluble carbonate and hydroxide salts of calcium and magnesium in catholyte.

$$
\begin{aligned}
& \mathrm{HCO}_{3}^{-}+\mathrm{OH}^{-}=\mathrm{CO}_{3}^{2-}+\mathrm{H}_{2} \mathrm{O}, \\
& \mathrm{Ca}^{2+}+\mathrm{CO}_{3}^{2-}=\mathrm{CaCO}_{3} \downarrow, \\
& \mathrm{Mg}^{2+}+2 \mathrm{OH}^{-}=\mathrm{Mg}(\mathrm{OH})_{2} \downarrow .
\end{aligned}
$$

As a result, calcium concentration in catholyte dropped to $0.5-0.4$, magnesium concentration reduced to $1.2-0.7$, total hardness decreased to $0.8-1.0 \mathrm{mmole} / \mathrm{dm}^{3}$ (Fig. 4). In anolyte, migration of hardness cations to catholyte through the diaphragm under the influence of electric current, resulted in reduction of calcium concentration to 2.0-1.6, magnesium concentration to 1.0-0.8 and total hardness decrease to $1.4-1.8 \mathrm{mmol} / \mathrm{dm}^{3}$.
The oxidation-reduction potential (Eh) of catholyte in processing natural water dropped to the reduction region from $+(0.16-0.18) \mathrm{V}$ to $-(0.2-0.3) \mathrm{V}$ (Fig. 5). When solution was reagent-alkalinized with alkali $\mathrm{NaOH}$, Eh decreased just to $+(0.10-0.06) \mathrm{V}$ due to $\mathrm{pH}$ growth in accordance with equation [18]

$$
\mathrm{Eh}=-0,0591 \mathrm{pH} \text {. }
$$

This was an indication of a significant effect exerted on the decrease in Eh of electrolytic hydrogen, which was released on the cathode and then dissolved in catholyte boosting its reducing properties [19].

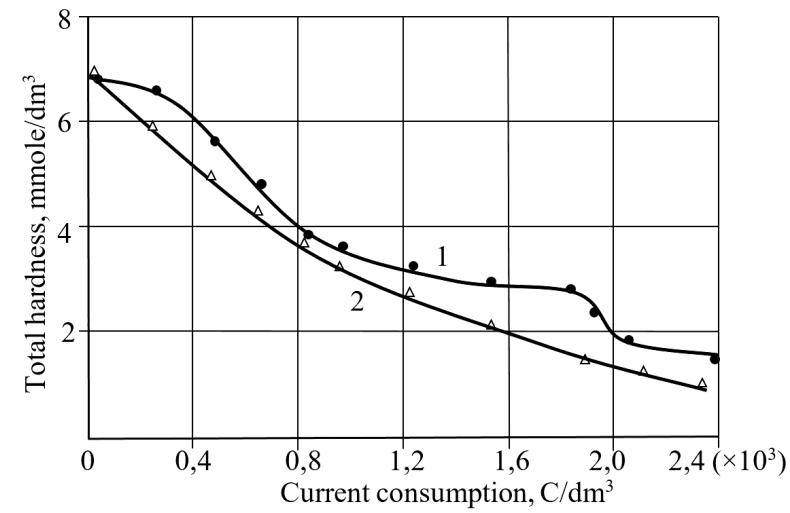

Fig. 4. Dependence of the total hardness on the current consumption in the treatment of natural water at carbonate hardness of $4.6 \mathrm{mmole} / \mathrm{dm}^{3}$ in a static diaphragm electrolyzer: 1 - anolyte; 2 - catholyte

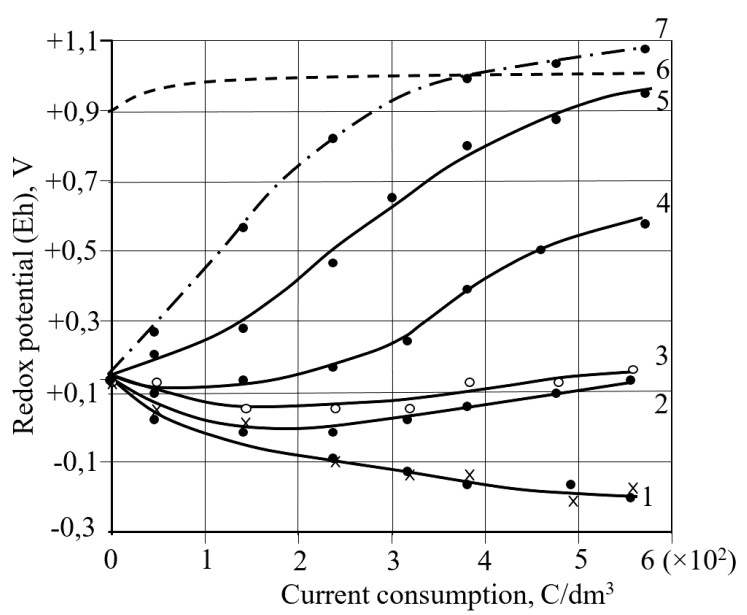

Fig. 5. Dependence of the change in anolyte Eh $(2-5,7)$ and catholyte (1) when treating aqueous solutions in a static diaphragm electrolyzer: $1-0.01 \mathrm{M} \mathrm{Na}_{2} \mathrm{SO}_{4}$ solution without taking into account the increase in $\mathrm{pH} ; 2-0.001 \mathrm{M} \mathrm{NaCl}$ solution without considering the decrease in $\mathrm{pH}$; $3-0.01 \mathrm{M}$ solution of $\mathrm{Na}_{2} \mathrm{SO}_{4}$ without considering the decrease in $\mathrm{pH} ; 4-0,005 \mathrm{M}$ solution of $\mathrm{NaCl}$ without considering the decrease in $\mathrm{pH} ; 5-0,02 \mathrm{M} \mathrm{NaCl}$ solution without considering the decrease in $\mathrm{pH} ; 6-0,02 \mathrm{M} \mathrm{NaCl}$ solution considering the decrease in $\mathrm{pH} ; 7-$ calculated line of the upper boundary of thermodynamic water stability

The Eh value of the natural water anolyte somewhat increased during electrolysis due to $\mathrm{pH}$ decrease according to equation (9) and oxygen dissolution. 
When treating water having $\mathrm{NaCl}$ concentration more than $0.02 \mathrm{M}$, the anolyte Eh increased to $+(0.9-1.1) \mathrm{V}$ exceeding the upper theoretical boundary of the thermodynamic stability of the aqueous medium [18] determined by equation

$$
\mathrm{Eh}=1.228-0.0591 \mathrm{pH}+0.0147 \lg \mathrm{P}_{\mathrm{O}_{2}},
$$

where $\mathrm{P}_{\mathrm{O}_{2}}=1 \mathrm{~atm}$ is oxygen pressure in water.

This is due to a simultaneous decrease in $\mathrm{pH}$ and discharge at the anode of $\mathrm{Cl}$-ions with production of chlorine gas $\mathrm{Cl}_{2}$. Chlorine gas dissolves in water to form hypochlorite acid $\mathrm{HOCl}$ which has strong oxidizing properties.

Comparison of the calculated [19] and the experimental electrochemical variation of $\mathrm{Eh}$ with the introduction of gases generally demonstrates their correspondence to each other (Table 1).

The calculated effect of gases on the change in the aqueous medium $\mathrm{Eh}$ at $\mathrm{pH}=7$

\begin{tabular}{|c|c|c|c|c|}
\hline \multirow{2}{*}{ Gas } & Equation of $\mathrm{Eh}$ & \multirow{2}{*}{$\begin{array}{l}\text { Gas solubility, } \\
\text { g/100 g water }\end{array}$} & \multicolumn{2}{l|}{ Maximun Eh change, V } \\
\cline { 4 - 5 } & & & calculation & experiment \\
\hline $\mathrm{O}_{2}$ & $\mathrm{Eh}=0.815+0.0148 \lg \left[\mathrm{O}_{2}\right]\left[\mathrm{H}^{+}\right]^{4}$ & $4.34 \times 10^{-3}$ & +0.401 & $+(0.1-0.2)$ \\
\hline $\mathrm{Cl}_{2}$ & $\mathrm{Eh}=1.395+0.0295 \lg \frac{\left[\mathrm{Cl}_{2}\right]}{\left[\mathrm{Cl}^{-}\right]^{2}}$ & 0.716 & +1.485 & $+(0.9-1.1)$ \\
\hline $\mathrm{H}_{2}$ & $\mathrm{Eh}=0.0295 \lg \frac{\left[\mathrm{H}^{+}\right]^{2}}{\left[\mathrm{H}_{2}\right]}$ & $1.6 \times 10^{-4}$ & -0.323 & $-(0.2-0.3)$ \\
\hline
\end{tabular}

During electrolysis, other ions migrate through the porous diaphragm to the electrodes. So, a simultaneous increase in concentration of sodium, potassium and iron cations in catholyte and chloride and sulfate anions in anolyte was observed. At the same time, heavy metals and other impurities in water can be precipitated by electrochemical alkalization in the cathode chamber.

\section{2. Softening of water under different patterns of water flow in electrode chambers}

During sequential movement of water in the electrode chambers of the electrolyzer and feeding it into the cathode chamber, the $\mathrm{pH}$ value in this chamber was set within 10.8-11.2. This caused formation of carbonates and hydroxides of calcium and magnesium. At the anode chamber exit, water $\mathrm{pH}$ decreased to 7.0-6.8. Total hardness of the treated water dropped from 4.6-5.0 to $2.6-3.4$ and reduction from $0.38-0.74$ to $0.28-0.46$ for acidity and from $6.9-7,8$ to $3.0-5.0 \mathrm{mmole} / \mathrm{dm}^{3}$ for alkalinity was observed.

For the reversed water flow, $\mathrm{pH}$ in the anode chambers was set at 6.5-6.6. Water $\mathrm{pH}$ at the exit from the cathode chambers increased by $0.5-0.6$ in comparison with its value for the initial water. An increase in $\mathrm{pH}$ of the treated water resulted in a decrease in its hardness by $0.2-0.6$, alkalinity by $0.4-0.6$, and acidity by $0.10-0.14 \mathrm{mmole} / \mathrm{dm}^{3}$.

More significant softening of water occurred in the schemes of parallel flow in the electrode chambers. Thus, when water was fed to the cathode chambers and moved in streams thru the electrode chambers in an equal proportion of the catholyte and anolyte flows, the catholyte $\mathrm{pH}$ increased to $10.7-11.2$ at a current consumption of $1600-2300 \mathrm{C} / \mathrm{l}$. This reduced its total hardness to $1.8-1.3 \mathrm{mmole} / \mathrm{dm}^{3}$ (Fig. 6). Catholyte alkalinity decreased initially as well but then increased slightly.

Anolyte $\mathrm{pH}$ decreased just to $6.20-6.05$ at the mentioned current consumptions. However, as the current consumption increased to $3800-4600 \mathrm{C} / \mathrm{l}, \mathrm{pH}$ subsequently dropped abruptly to 3.3-2.6. Anolyte acidity increased accordingly.

Due to the migration of $\mathrm{Ca}^{2+}$ and $\mathrm{Mg}^{2+}$ ions from the anode chambers to the cathode ones which occurred under the action of electric current, the total anolyte hardness decreased to $1.6-1.3 \mathrm{mmole} / \mathrm{dm}^{3}$. In this case, the change of hardness in anolyte was less intensive than in catholyte. The final values of catholyte and anolyte stiffness were practically the same (Fig. 6).

Table 1 Reduction of hardness salt concentrations in anolyte and catholyte has resulted in a change in the rest of parameters of the entire volume of treated water. Thus, $\mathrm{pH}$ of the catholyte and anolyte mixture decreased on average by $0.4-0.8$, alkalinity decreased by $3.6-4.0 \mathrm{mg} / \mathrm{l}$ but acidity increased by $0.2-0.3 \mathrm{mmole} / \mathrm{dm}^{3}$.

In the parallel scheme of water flow and its feed to the anode chambers, the $\mathrm{pH}$ and alkalinity of catholyte increased more intensively and $\mathrm{pH}$ and acidity of anolyte decreased less intensively. However, difference in the changes of the total hardness of catholyte, anolyte and their mixture was insignificant. Some decrease in $\mathrm{pH}$ and an increase in acidity of the mixture of anolyte and catholyte by 0.9-1.0 units contributed to its stabilization, which eliminated an additional introduction of acid which is done in reagent water softening with the use of lime and soda. So, as calculations show, stability index of softened water was within $-(0.08-0.15)$ units eliminating the need for additional acidation of water.

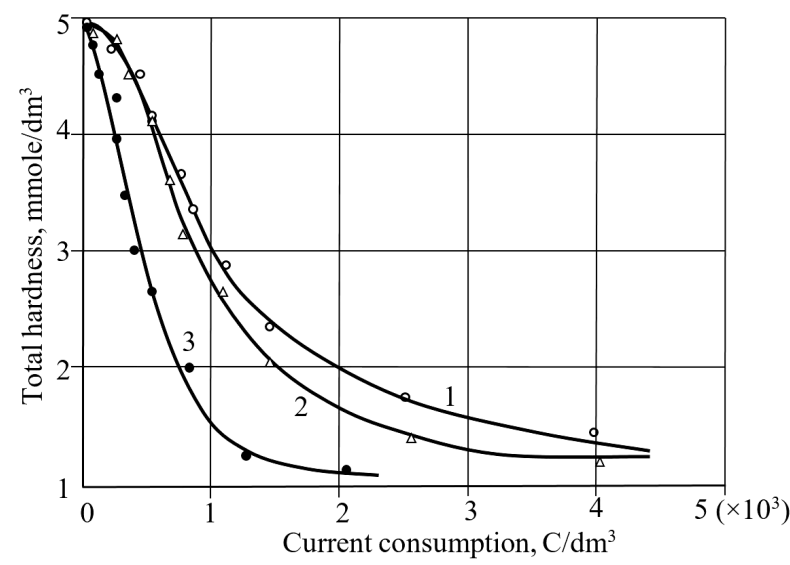

Fig. 6. Dependence of hardness on current consumption in treating water with parallel flows in a flow-type diaphragm electrolyzer: 1 - anolyte; 2 - catholyte; 3 -a mixture of catholyte and anolyte

The data obtained in processing natural water by parallel streams with various consumption ratios of catholyte to anolyte from 3:7 to 7:3 show that the ratio does not practically affect $\mathrm{pH}$ of catholyte and anolyte. At the same time, a decrease in the consumption ratio of catholyte and 
anolyte to (9.5-8.5):(0.5-1.5) or less leads to a slowdown in the change of water $\mathrm{pH}$ in the electrode chambers and, consequently, to a decrease in the degree of water softening.

Generalized indicators of natural water softening at various schemes of its movement in the electrode chambers of the diaphragm electrolyzer are given in Table. 2.

The change in the value of the treated water Eh is more complex and is determined by the final stage of water treatment in the electrode chamber. In a sequential scheme with water supply to the anode chamber, the value of Eh decreased from $+(0.23-0.25) \mathrm{V}$ to $+(0.068-0.13) \mathrm{V}$ at the outlet from the cathode chamber. When water is fed into the cathode chamber and discharged from the anode chamber, the value of Eh varies insignificantly compared to the initial water.

In a parallel scheme with feeding into the cathode chamber, catholyte Eh decreased from $+(0.23-0.25) \mathrm{V}$ to $+(0.14-0.17) \mathrm{V}$, anolyte Eh increased to $+(0.40-0.42) \mathrm{V}$, Eh of the catholyte and anolyte mixture was $+(0.32-0.46) \mathrm{V}$. When feed was done to the anode chamber, catholyte Eh ranged from $+0.10 \mathrm{~V}$ to $-0.03 \mathrm{~V}$, anolyte Eh increased to $+(0.40-0.46) \mathrm{V}$. Eh of the catholyte and anolyte mixture was $+(0.32-0.40) \mathrm{V}$. Thus, regardless of the water flow pattern in the parallel scheme, the value of Eh of the entire water flow increased slightly which contributed to its disinfection. In this case, it is more preferable to use feed to the anode chamber in which the whole water stream is initially exposed to oxidation processes.

The most significant degree of water softening at the smallest electricity consumptions was observed when water was fed to the anode chambers and moved in parallel streams in the electrode chambers. At the same time, water was stabilized and disinfected. The total hardness of natural water was reduced to $1.4-1.6 \mathrm{mmole} / \mathrm{dm}^{3}$, alkalinity up to $3.8-4.3 \mathrm{mmole} / \mathrm{dm}^{3}, \mathrm{pH}$ by $0.3-0.6$ and acidity practically did not change.

Based on the studies, design of an industrial monopolar electrolyzer with an inactive diaphragm for electrochemical change of $\mathrm{pH}$ and Eh has been developed. The electrolyzer feature is that it uses a solid anode and a perforated cathode or perforated electrodes in a close contact with the diaphragm. The design of the electrode block enables electrochemical alteration of $\mathrm{pH}$ and $\mathrm{Eh}$ of the aqueous medium directly in the flowing water at low (up to 8-12 V) electrolysis voltages which makes it possible to reduce the power consumption for softening to 1.4-1.9 W-hr per 1 mmole of hardness.

By the degree of softening and the essence of the ongoing processes, electrochemical softening is in many ways analogous to reagent alkalinization. Unlike reagent softening, use of electrochemical $\mathrm{pH}$ change avoids the increase in the residual hardness of treated water which occurs when excess lime is introduced.
The recommended process scheme for softening involves the parallel movement of catholyte and anolyte streams in the electrolysis cell in a consumption ratio (7-8):(3-2) and their separate extraction from the electrode chambers. Catholyte is then filtered to remove insoluble hardness salts and mixed with anolyte. The degree of water softening is only regulated by changing direct current strength applied to the electrodes.

\section{Discussion of the results obtained in the studies of water softening in the diaphragm electrolyzer}

Studies of electrochemical water softening have shown that the main process determining the degree of removal of hardness salts is alkalinization of the catholyte in the cathode chamber. By increasing $\mathrm{pH}$, hydrocarbonate anions are converted to carbonate anions with the formation of poorly soluble calcium carbonate. Magnesium is precipitated as a hydroxide. Removal of hardness ions in anolyte occurs as a result of their migration through a porous diaphragm from the anode chamber to the cathode chamber under the action of electric current.

Effectiveness of hardness salts precipitation increases with increase in water mineralization. In this case, the current transfer is intensified by indifferent $\mathrm{Na}^{+}, \mathrm{SO}_{4}^{2-}$ and other ions, which determine the degree of accumulation of acid in anolyte and alkali in catholyte, respectively.

The change in oxidation-reduction properties of anolyte and catholyte was studied. The determinants of the change in Eh are the shift in $\mathrm{pH}$ of the aqueous medium and dissolution of the gases evolved in the course of electrolysis, such as hydrogen, oxygen and gaseous chlorine. In anolyte, due to formation of hypochlorite acid in chlorine evolution and the decrease in $\mathrm{pH}$, the value of the aqueous medium Eh can rise to the upper limit of the thermodynamic stability of water. In fact, the electrochemical increase of anolyte Eh is equivalent to the introduction of chlorine-containing reagents into water in order to disinfect it.

Influence of various schemes of water movement in the electrode chambers of the flow diaphragm electrolyzer on the degree of water softening was studied. The results have shown that sequential movement through the electrode chambers with filtration through the diaphragm made it possible to soften water only to $2.4-4.4 \mathrm{mmole} / \mathrm{dm}^{3}$. When water was fed to the cathode chambers and removed from the anode ones due to the initial increase in catholyte $\mathrm{pH}$, a higher degree of softening was achieved. With the reverse movement of water, a higher increase in catholyte $\mathrm{pH}$ but a low degree of softening was observed. This is explained by

Table 2

Indicators of water softening at various schemes of its movement in the electrode chambers of the diaphragm electrolyzer

\begin{tabular}{|c|c|c|c|c|c|}
\hline \multirow{2}{*}{$\begin{array}{c}\text { Indicators of } \\
\text { water softening and } \\
\text { parameters of its treatment }\end{array}$} & \multirow[b]{2}{*}{ Initial water } & \multicolumn{2}{|c|}{ Sequential movement } & \multicolumn{2}{|c|}{ Parallel movement } \\
\hline & & $\begin{array}{l}\text { Feed to cathode } \\
\text { chambers }\end{array}$ & $\begin{array}{l}\text { Feed to anode } \\
\text { chambers }\end{array}$ & $\begin{array}{l}\text { Feed to cathode } \\
\text { chambers }\end{array}$ & $\begin{array}{l}\text { Feed to anode } \\
\text { chambers }\end{array}$ \\
\hline $\mathrm{pH}$ & $7.2-7.5$ & $6.8-7.0$ & $7.9-8.2$ & $6.7-6.9$ & $6.7-6.9$ \\
\hline Total hardness, mmole $/ \mathrm{dm}^{3}$ & $4.6-5.0$ & $2.4-3.0$ & $4.4-4.8$ & $1.4-1.6$ & $1.4-1.6$ \\
\hline Alkalinity, mmole $/ \mathrm{dm}^{3}$ & $6,9-7.8$ & $3.0-3.4$ & $6.5-6.8$ & $3.3-3.8$ & $3.8-4.3$ \\
\hline Acidity, mmole/ $/ \mathrm{dm}^{3}$ & $0.4-0.7$ & $2.4-3.0$ & $4.4-4.8$ & $1.4-1.6$ & $1.4-1.6$ \\
\hline Curent consumption, $\mathrm{C} / \mathrm{l}$ & - & $1200-1400$ & $1000-1500$ & $1200-1400$ & $1000-1200$ \\
\hline $\begin{array}{l}\text { Current consumption, } \\
\mathrm{W} \text {-hr/mmole of hardness }\end{array}$ & - & $3.6-5.3$ & $2.2-5.9$ & $2.5-3.8$ & $1.4-1.9$ \\
\hline
\end{tabular}


the fact that hydrocarbonate anions are converted to carbon dioxide gas during the initial acidation of water in the anode chamber. This process reduces carbonate alkalinity of water and lessens the possibility of calcium carbonate formation in the cathode chamber.

With parallel movement of water in the electrode chambers with filtration of a part of water through the diaphragm and a different ratio of catholyte and anolyte flows, a higher degree of water softening was observed. It is preferable to feed water to the anode chamber. In this mode, colmatation of the diaphragm pores by poorly soluble salts of hardness is also prevented. Since calcium and magnesium salts are formed in catholyte, the stream of acidified anolyte from the anode chamber through the filter diaphragm prevents their precipitation in the diaphragm pores.

Hydrogen and hydroxyl ions are formed in an equivalent amount in anolyte and catholyte but some hydroxyl ions are spent on precipitation of hardness salts. As a result, $\mathrm{pH}$ of catholyte and anolyte mixture is somewhat reduced which ensures stabilization of the softened water.

Reduction of catholyte/anolyte consumption ratio to less than (9.5-8.5):(0.5-1.5) leads to a smaller degree of water softening. Because of a decrease in anolyte consumption in the anode chamber, formation of a significant excess of hydrogen ions takes place, and these ions migrate through the diaphragm to the cathode chamber and neutralize some of the hydroxyl ions.

The developed diaphragm electrolyzer with perforated electrodes pressed to the both sides of the diaphragm ensures minimization of the distance between cathode and anode and lower electrolysis voltage. In addition, electric current passage only through the diaphragm and the outside surfaces of the electrodes is ensured. As a result, energy consumption for water softening is reduced.

\section{Conclusions}

1. It was shown that the electrochemical softening of water in the cathode chamber of the diaphragm electrolyzer occurred due to an increase in catholyte $\mathrm{pH}$ to $10.4-10.6$ in the anode chamber due to the migration of calcium and magnesium ions through the diaphragm to the cathode chamber. Hardness of softened water was reduced to 1.4-1.6 mmole/ $\mathrm{dm}^{3}$. The value of anolyte Eh during electrolysis was increased by lowering $\mathrm{pH}$ and dissolving oxygen. In the presence of chlorides in water due to lower $\mathrm{pH}$ and formation of chlorine, anolyte Eh can grow to $+(0,9-1,1) \mathrm{V}$ which allows disinfection of the softened water.

2. It has been established that the greatest degree of water softening in a flow-type electrolyzer at the lowest consumption of electric power was observed when water was fed to the anode chamber, a part of water was filtered into the cathode chamber and when water was moved in parallel flows in the electrode chambers at a ratio of catholyte and anolyte flows (7-8):(3-2). Due to the treatment of the entire water flow in the anode chamber and $\mathrm{pH}$ of the mixture of catholyte and anolyte removed from the electrode chambers, disinfection and stabilization of the softened water occured. The proposed design of the diaphragm electrolyzer with perforated electrodes pressed against the diaphragm ensures reduction of energy consumption for water softening.

\section{References}

1. Frog, B. Vodopodgotovka [Water conditioning] [Text] / B. Frog, A. Pervov. - Moscow: Publishers Association building universities, 2014. - $512 \mathrm{p}$.

2. Van der Bruggen, B. Cost-benefit analysis of central softening for production of drinking water [Text] / B. Van der Bruggen, H. Goossens, P. A. Everard, K. Stemgee, W. Rogge // Journal of Environmental Management. - 2009. - Vol. 91, Issue 2. P. 541-549. doi: 10.1016/j.jenvman.2009.09.024

3. Cuda, P. Reverse osmosis in water treatment for boilers [Text] / P. Cuda, P. Pospisil, J. Tenglerova // Desalination. - 2006. Vol. 198, Issue 1-3. - P. 41-46. doi: 10.1016/j.desal.2006.09.007

4. Nanda, D. Effect of solution chemistry on water softening using charged nanofiltration membranes [Text] / D. Nanda, K.-L. Tung, C.-C. Hsiung, C.-J. Chuang, R.-C. Ruaan, Y.-C. Chiang et. al. // Desalination. - 2008. - Vol. 234, Issue 1-3. - P. 344-353. doi: 10.1016/j.desal.2007.09.103

5. Entezari, M. Water softening by combination of ultrasound and ion exchange [Text] / M. Entezari, M. Tahmasbi // Ultrasonics Sonochemistry. - 2009. - Vol. 16, Issue 3 - P. 356-360. doi: 10.1016/j.ultsonch.2008.09.008

6. Rogov, V. M. Elektrokhimicheskaya tekhnologiya izmeneniya svoystv vody [The electrochemical technology is changing the properties of water] [Text] / V. M. Rogov, V. L. Filipchuk. - Lviv: Vishcha School, 1989. - 127 p.

7. Gabrielli, C. Electrochemical water softening: principle and application [Text] / C. Gabrielli, G. Maurin, H. Francy-Chausson, P. Thery, T. T. M. Tran, M. Tlili // Desalination. - 2006. - Vol. 201, Issues 1-3. - P. 150-163. doi: 10.1016/j.desal.2006.02.012

8. Zhi, S. A novel combined electrochemical system for hardness removal [Text] / S. Zhi, S. Zhang // Desalination. - 2014. Vol. 349. - P. 68-72. doi: 10.1016/j.desal.2014.06.023

9. Malakootian, M. Performance evaluation of electrocoagulation process using iron-rod electrodes for removing hardness from drinking water [Text] / M. Malakootian, H. J. Mansoorian, M. Moosazadeh // Desalination. - 2010. - Vol. 255, Issue 1-3. - P. 6771. doi: $10.1016 /$ j.desal.2010.01.015

10. Zeppenfeld, K. Electrochemical removal of calcium and magnesium ions from aqueous solutions [Text] / K. Zeppenfeld // Desalination. - 2011. - Vol. 277, Issues 1-3. - P. 99-105. doi: 10.1016/j.desal.2011.04.005 
11. Hasson, D. Removal of scale-forming ions by a novel cation-exchange electrochemical system - A review [Text] / D. Hasson, H. Shemer, R. Semiat // Desalination and Water Treatment. - 2015. - Vol. 57, Issues 48-49. - P. 23147-23161. doi: 10.1080/1944 3994.2015.1098806

12. Park, J.-S. Removal of hardness ions from tap water using electromembrane processes [Text] / J.-S. Park, J.-H. Song, K.-H. Yeon, S.-H. Moon // Desalination. - 2007. - Vol. 202, Issue 1-3. - P. 1-8. doi: 10.1016/j.desal.2005.12.031

13. Seo, S.-J. Investigation on removal of hardness ions by capacitive deionization (CDI) for water softening applications [Text] / S.-J. Seo, H. Jeon, J. K. Lee, G.-Y. Kim, D. Park, H. Nojima et. al. // Water Research. - 2010. - Vol. 44, Issue 7. - P. $2267-2275$. doi: $10.1016 /$ j.watres.2009.10.020

14. Zaslavschi, I. Electrochemical $\mathrm{CaCO}_{3}$ scale removal with a bipolar membrane system [Text] / I. Zaslavschi, H. Shemer, D. Hasson, R. Semiat // Journal of Membrane Science. - 2013. - Vol. 445. - P. 88-95. doi: 10.1016/j.memsci.2013.05.042

15. Demidova, Yu. M. Use of a resource-saving technology in water treatment systems [Text] / Yu. M. Demidova, E. O. Shinkevich, A. G. Laptev // Thermal Engineering. - 2010. - Vol. 57, Issue 8. - P. 657-661. doi: 10.1134/s0040601510080057

16. Bagrii, V. A. Softening of calcium-hydrocarbonate water in a flow-through electrolyzer with a filtrating cartridge [Text] / V. A. Bagrii, R. D. Chebotaryova, S. Yu. Bashtan, S. V. Remez, V. V. Goncharuk // Journal of Water Chemistry and Technology. 2008. - Vol. 30, Issue 2. - P. 100-104. doi: 10.3103/s1063455x08020069

17. Hasson, D. Calcium carbonate hardness removal by a novel electrochemical seeds system [Text] / D. Hasson, G. Sidorenko, R. Semiat // Desalination. - 2010. - Vol. 263, Issue 1-3. - P. 285-289. doi: 10.1016/j.desal.2010.06.036

18. Zito, R. Electrochemical Water Processing [Text] / R. Zito. - John Wiley \& Sons, 2011. - 314 p. doi: 10.1002/9781118104675

19. Filipchuk, V. L. Zastosuvanya gaziv dlya regulyuvannya okisno-vidnovnih vlastivostey vody [The uze of gases for regulation redox properties of water] [Text] / V. L. Filipchuk, L. V. Filipchuk // Journal of Engineering Academy of Ukraine. - 2016. - Issue 1. P. $178-183$. 